\title{
Improving the quality of mental health services using patient outcome data: making the most of HoNOS
}

\author{
Mike J. Crawford, ${ }^{1,2}$ Mo Zoha, ${ }^{2}$ Alastair J. D. Macdonald, ${ }^{3}$ David Kingdon ${ }^{4}$
}

BJPsych Bulletin (2017) 41, 172-176, doi: 10.1192/pb.bp.116.054346

${ }^{1}$ College Centre for Quality Improvement, Royal College of Psychiatrists, London, UK; ${ }^{2}$ Central and North West London NHS Foundation Trust, London, UK; ${ }^{3}$ South London and Maudsley NHS Foundation Trust, London, UK; ${ }^{4}$ Southern Health NHS Foundation Trust, Southampton, UK

Correspondence to Mike J. Crawford (m.crawford@imperial.ac.uk)

First received 12 Apr 2016, final revision 20 Jun 2016, accepted 8 Jul 2016

(C) 2017 The Authors. This is an openaccess article published by the Royal College of Psychiatrists and distributed under the terms of the Creative

Commons Attribution License (http:// creativecommons.org/licenses/by/ 4.0), which permits unrestricted use, distribution, and reproduction in any medium, provided the original work is properly cited.
Summary Efforts to assess and improve the quality of mental health services are often hampered by a lack of information on patient outcomes. Most mental health services in England have been routinely collecting Health of the Nation Outcome Scales (HoNOS) data for some time. In this article we illustrate how clinical teams have used HoNOS data to identify areas where performance could be improved. HoNOS data have the potential to give clinical teams the information they need to assess the quality of care they deliver, as well as develop and test initiatives aimed at improving the services they provide.

Declaration of interest None.
A commitment to improving the quality of healthcare is central to the aims of the National Health Service (NHS). ${ }^{1}$ This commitment involves developing and evaluating new interventions and treatments, obtaining feedback from patients and learning from mistakes. ${ }^{2}$ It also involves monitoring and improving patient outcomes. Despite repeated calls for greater use of patient outcome measures in mental health, available evidence suggests that very few services use them to monitor change over time. ${ }^{3}$ There are a number of important barriers which make it difficult to implement systems for monitoring patient outcomes, including access to reliable and valid measures, the need to protect patient confidentiality and the time and money needed to collect, analyse and report data., ${ }^{4,5}$

While many initiatives aimed at improving the quality of NHS services have been 'top-down', it is widely acknowledged that front-line clinicians have a key role in efforts to improve service quality. ${ }^{6,7}$ However, unless clinical teams have access to information about patient outcomes, they cannot assess their performance or identify areas where performance could be improved.

For the past 20 years the Health of the Nation Outcome Scales (HoNOS) have provided a means of assessing the health and social functioning of people who use mental health services. ${ }^{8}$ HoNOS is a clinician-rated outcome measure comprising 12 scales covering symptoms, functioning, social relationships and environmental issues. Each domain is rated by the treating clinician on the scale of 0 to $4: 0$ means no problem, 1 means a problem that probably requires no intervention and 2, 3 and 4 correspond to 'mild', 'moderate' and 'severe' problems. They are rated by staff using all available information - not as a questionnaire or interview based on the worst state in the reference period, usually 2 weeks. There is a glossary, and training in their use is generally recommended. ${ }^{9}$ Although it is possible to calculate a total HoNOS score for a patient, individual scores on each of the 12 scales provide a better guide to the problems they are experiencing and targets for future interventions and treatments. Originally developed to measure the health and social functioning of working-age adults with severe mental illness, the scales have been modified to assess mental health of older adults (HoNOS65+), ${ }^{10}$ children and adolescents (HoNOSCA), ${ }^{11}$ people with intellectual disability (HONOS-LD), ${ }^{12}$ in secure settings (HoNOS-Secure) ${ }^{13}$ and with acute brain injury (HoNOS-ABI). ${ }^{14}$

Use of HoNOS in mental health services in England was patchy until work started on the development of a commissioning tariff based on a Mental Health Clustering 
Tool, which needed HoNOS scores to be completed on all patients who are in scope of the mental health tariff. ${ }^{15}$ While these plans are still in development, this initiative has led to widespread use of HoNOS throughout the country. In recent years clinicians have begun to consider how these data might be used to assess and improve the quality of care they provide. In the next section we present how clinical teams in three trusts have used HoNOS data to identify problems with the care they provide and plan ways to improve it.

\section{HoNOS use - examples of application}

\section{Example 1: using HoNOS to examine reasons for admission}

Reasons for admission to hospital or to crisis resolution/ home treatment (CRHT) teams are poorly understood yet very important in terms of ensuring that available resources are used effectively. As the number of beds decreases, thresholds for admission are becoming increasingly important to assess at a service level.

A team in Southampton used routine HoNOS data to explore mental health problems (such as psychotic symptoms, suicidality and aggression) experienced by adults who were admitted to in-patient units and people referred to CRHT services. They compared the proportion of people who had problems requiring intervention (a score of 2 or more on different HoNOS items) among 3409 people admitted to hospital and 2991 referred to local crisis teams (Table 1). The most prevalent problems among people referred to either service were suicidality and agitation, with levels of agitation higher among those admitted to hospital. Nonetheless, clinicians were surprised to see that only around half of patients admitted to hospital and 39\% taken on by crisis teams scored as requiring intervention for suicidality and/or agitation. Even when people with significant problems with psychosis or accommodation status were included, a significant minority did not appear to have major problems requiring intervention.

When these findings were discussed within teams, clinicians raised the possibility that people may be being referred to in-patient or CRHT services because of a combination of different problems at less severe level or that staff were under-scoring these items. It also led to discussions about the level of severity at which people were being referred to these services. Discussions based on this

\begin{tabular}{|c|c|c|}
\hline Scores $>2$ on HoNOS items & $\begin{array}{c}\text { Hospital } \\
n=3409 \\
\%\end{array}$ & $\begin{array}{c}\text { Crisis team } \\
n=2991 \\
\%\end{array}$ \\
\hline 1: Agitation & 29 & 16 \\
\hline 2: Suicidality & 22 & 27 \\
\hline 3: Accommodation & 6 & 5 \\
\hline 4: Delusions and hallucinations & 13 & 9 \\
\hline 1 or 2 & 47 & 39 \\
\hline 1 or 2,3 or 4 & 66 & 53 \\
\hline
\end{tabular}

information led to a review of in-patient services (numbers of beds in the area were higher than in other comparable catchment areas), ${ }^{16}$ and a review of thresholds for access to CHRT services.

\section{Example 2: outcomes of patients treated by assessment and brief treatment teams}

Community mental health teams in central London used routine data from HoNOS to examine outcomes of treatment. Changes in mean HoNOS scores were calculated for patients under the care of assessment and brief treatment teams between April 2013 and September 2014 by comparing the mean severity from initial review with that from a follow-up. Scores of 3 (moderate) or 4 (severe) were categorised as 'high' and scores of 0 (absent), 1 (minimal) or 2 (mild) were categorised as 'low', and proportions of people moving between low and high scores were plotted (Fig. 1). In Fig. 1 differences in severity of each subscale of HoNOS are presented for people in clusters 1-5 (single non-psychotic episode), clusters 6-8 (enduring non-psychotic) and clusters 10-15 (psychosis). The data showed that a smaller proportion of people in clusters 6 to 8 had made progress during their time with teams; among people in clusters 6 to 8 , fewer who had high scores at baseline had lower levels at follow-up, especially compared with people in clusters 10 to 15 . When data were examined from four other sector services in the trust a similar pattern emerged, with a greater proportion of patients in clusters 6 to 8 failing to show evidence of improvement or problems becoming more severe between the two time points compared with people in clusters 10 to 15 .

When these data were presented to front-line staff they commented that it can be difficult to help meet the needs of people in clusters 6-8 (predominately people with personality disorder) through the types of interventions available to staff working in assessment and brief treatment teams. Although staff working in these services are able to refer patients to a local specialist personality disorder service, many do not want the group-based psychological treatment offered by this service or are too chaotic and poorly motivated to engage in psychological treatment. Discussions prompted by a review of these data led to the development and piloting of a six-session brief intervention package for people with personality disorder offered by members of the local specialist team (details available from the authors on request). This package of treatment is based on National Institute for Health and Care Excellence (NICE) guidelines ${ }^{17}$ and focuses on psychoeducation and skills training. It is hoped that some people who initially reject the offer of longer-term psychological treatment can be engaged through this extended assessment and that others will benefit more from this approach than they do from the care they are currently receiving.

\section{Example 3: comparing outcomes of older adults admitted to in-patient units}

Staff working on an in-patient mental health unit for older adults with dementia and other organic conditions used routine HoNOS65+ data to examine outcomes of people admitted to their service. It was noted that over a 3-year 


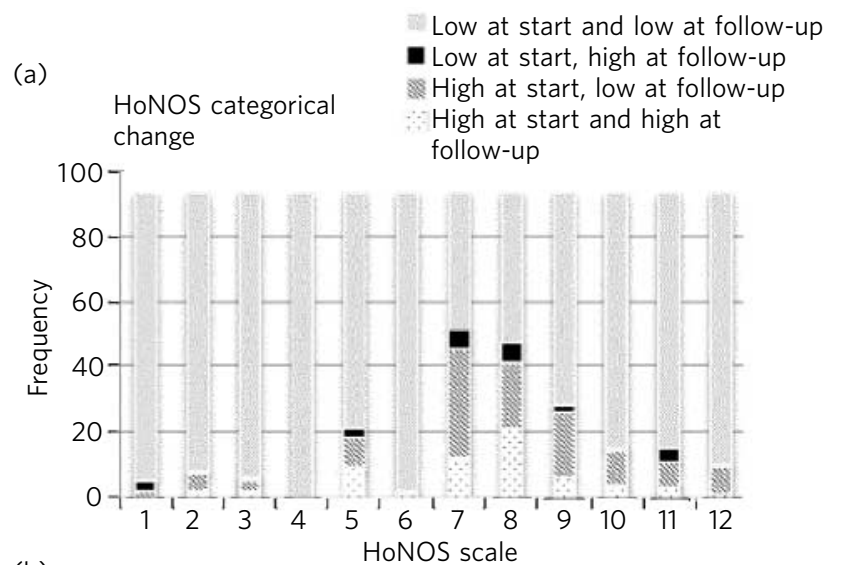

(b)

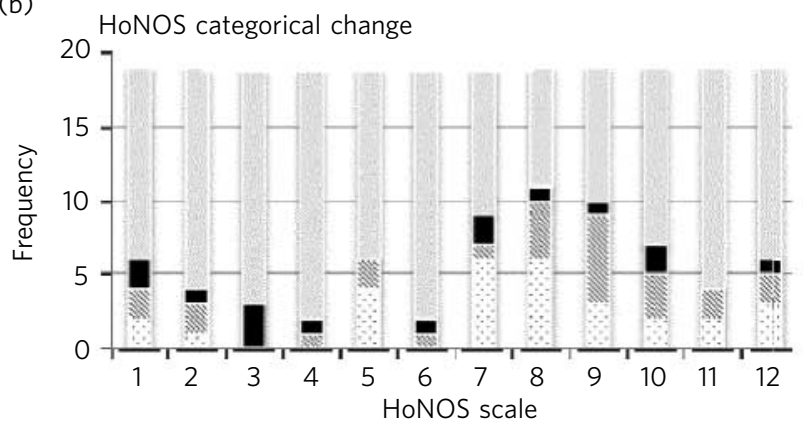

(c)

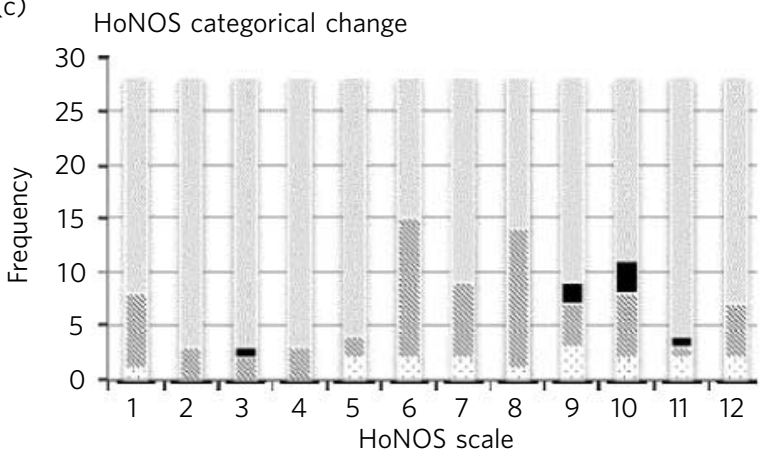

Fig. 1 Changes in HoNOS scores among people treated by assessment and brief treatment teams. (a) Clusters 1-5; (b) Clusters 6-8; (c) Clusters 10-15.

period the mean percentage improvement in scores on the depression scale of the HoNOS65+ declined (Fig. 2). Outcomes can only be properly understood with reference to context and interventions. These data were therefore compared with those from a similar unit in the same trust with the same operational policy, lengths of stay, diagnostic and demographic characteristics, and initial severity scores. Data from this unit showed that mean percentage improvement on the depression scale over the same period was approximately $50 \%$. The team did not have and still do not have direct data on interventions, but in 2001 there was a pilot study of the systematic recording of care plans, and these data were linked to outcomes data. It transpired that in the unit with the poorer outcomes, all patients with dementia were automatically given night-time benzodiazepine hypnotics. Furthermore, there was a strong association between being given nighttime benzodiazepines and poor outcomes. During

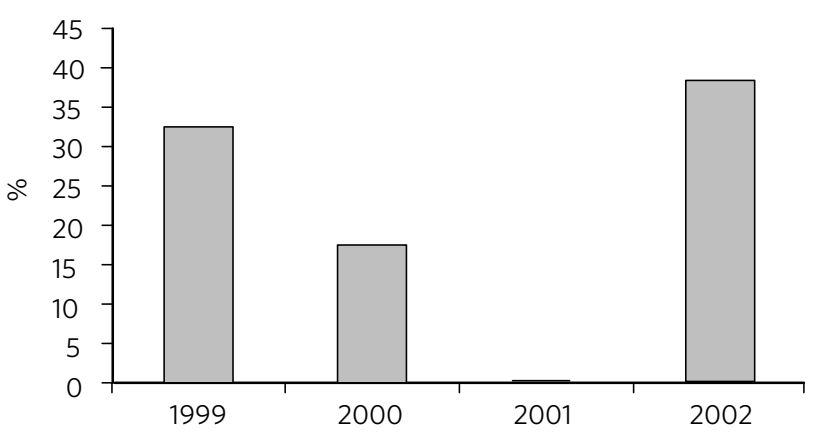

Fig. 2 Mean percentage improvement in HoNOS65+ depression scale among patients admitted to an older adult mental health unit.

discussion with the teams it was agreed that routine use of benzodiazepines was a plausible explanation of poor outcomes and this policy was revoked. Over the course of the next year mental health outcomes of patients admitted to the unit improved (Fig. 2).

\section{Discussion}

The examples given above illustrate how front-line clinical teams have used routinely collected HoNOS data to examine and to try to improve the outcomes of the patients they treat. While changes to mental health services will continue to be made in response to new national policy directives, new research findings and new technologies, we believe that one of the most effective ways to improve service quality is 'bottom-up': through local teams using local data to drive change. However, front-line clinicians face a number of significant challenges when trying to assess and improve the quality of the care they provide. Chief among these are limited time and other resources needed to collect data on patient outcomes. We are aware of numerous occasions when clinical teams have made changes to the services they provide but have not had the resources to examine whether these changes led to improvements in patient care. In other instances, baseline audits are conducted that identify problems in a service that teams try to correct, but staff have not had time to assess whether these changes benefited patients. To fulfil the NHS promise to patients to continuously work to improve service quality, clinical teams need to be able to access data on patient outcomes. Yet the experience of participants in the UK Routine Clinical Outcomes Network (www.ukrcom.org) suggests that very few services provide outcomes data to their teams. Embarking on new efforts to collect patient- and staff-rated outcomes is expensive and time consuming. By contrast, routinely collected HoNOS data in England provide an important source of clinician-rated patient outcomes that do not require additional resources to be spent and can be used to assess and improve the quality of care that teams provide.

\section{Challenges to widespread HoNOS use}

While the vignettes above illustrate how HoNOS data have been used by front-line clinical teams, a number of obstacles 
need to be overcome if this approach is to become more widespread.

First, concerns have been raised about the quality of routine HoNOS data. ${ }^{18}$ Available evidence suggests that if staff are provided with appropriate support and training, HoNOS can be used to generate reliable information that can be used to compare different services and examine changes in patient outcomes over time. ${ }^{19}$ Second, IT systems in trusts need to be able to generate reports on outcome data in a form that clinical teams find useful. Third, data from HoNOS and other routine outcomes scales need to be interpreted cautiously. Random variation and subtle changes in practice and case-mix may have led to changes in patients outcomes over time. Separating real and spurious differences can be difficult. ${ }^{20}$ Finally, teams need to be given time and space to examine their data, learn from them and use them to evaluate their efforts to improve service quality. If staff are supported to generate reliable data and systems are available to deliver data to front-line clinical teams, then these data have the potential to be used in clinical audit and in alternative models for improving service quality, such as Plan-Do-Study-Act cycles. ${ }^{21}$ The latter approach may have some advantages over traditional audits because it allows the impact of changes in practice to be examined more frequently and provides a more iterative approach to developing changes aimed at improving patient outcomes. $^{22,23}$

At present, most staff see collecting outcome data as an 'invisible task', in which time is spent collecting and entering data for no purpose. ${ }^{24}$ If systems can be implemented that deliver feedback to staff on service-level patient outcomes, staff are more likely to value collecting these data. For instance, in South London and Maudsley NHS Foundation Trust and Central and North West London NHS Foundation Trust, clinicians have organised meetings for staff in which HoNOS data are presented and discussed. Feedback from staff attending these meetings has shown they value getting this information and their comments have been used to refine the way that data are collated and presented (most staff indicated a preference for the categorical change model presented in Fig. 1 rather than changes in total HoNOS scores).

While HoNOS scores collected through the current mental health payment initiative ${ }^{15}$ provide a rich source of routine data on patient outcomes, the timing of assessments is unlikely to be optimal for evaluating the impact of treatments and services. Further work is needed to establish when outcome assessments are best undertaken in different settings to compare services and assess the impact of quality improvement initiatives.

HoNOS data are not the only form of evidence that mental health services collect. For instance, psychiatric inpatients are asked to complete the 'friends and family test' (a two-item short patient-rated experience measure). ${ }^{25}$ However, there is very little evidence that these data are being fed back to clinicians to allow them to reflect on differences in levels of patient satisfaction over time or between different teams. ${ }^{26}$ Such data also have the potential to stimulate bottom-up efforts to assess and improve service quality if steps are taken to use them in this way. One of the great strengths of HoNOS data is that they provide a summary of mental health, behavioural problems and social factors. Although this means that HoNOS can be used under circumstances where poor mental health or impaired cognition may limit the value of patient-rated data, there are drawbacks to relying solely on clinician-rated outcomes. The possibility that outcome data could be used to pay services based on patient outcomes could paradoxically reduce their value as a means to assess and improve service quality. ${ }^{27}$ This is commonly known as Goodhart's law after the British economist Charles Goodhart: 'When a measure becomes a target, it ceases to be a good measure. ${ }^{28}$

Mental health trusts in England are currently collecting large amounts of outcome data using HoNOS. We believe that efforts by mental health services to use HoNOS data and other routinely collected patient outcomes have the potential to make better use of available resources and engage front-line clinicians in efforts to improve patient outcomes.

\section{About the authors}

Mike J. Crawford, Director, College Centre for Quality Improvement, Royal College of Psychiatrists, London, and Central and North West London NHS Foundation Trust, London, UK; Mo Zoha, Consultant Psychiatrist, Central and North West London NHS Foundation Trust, London, UK; Alastair J. D. Macdonald, Professor of Old Age Psychiatry, Trust Clinical Outcomes Team, South London and Maudsley NHS Foundation Trust, London, UK; David Kingdon, Clinical Services Director, Southern Health NHS Foundation Trust, Southampton, UK.

\section{References}

1 Department of Health. The NHS Constitution for England. Department of Health, 2015.

2 Department of Health. High Quality Care for All: NHS Next Stage Review Final Report. TSO (The Stationery Office), 2008

3 Gilbody SM, House AO, Sheldon TA. Psychiatrists in the UK do not use outcomes measures. National survey. Br J Psychiatry 2002; 180: 101-3.

4 Slade MG, Thornicroft G, Glover G. The feasibility of routine outcome measures in mental health. Soc Psychiatry Psychiatr Epidemiol 1999; 34: 243-9.

5 Lelliot P. Secondary uses of patient information. Adv Psychiatr Treat 2003; 9: 221-8.

6 Berwick DM. Broadening the view of evidence-based medicine. Qual Saf Health Care 2005; 14: 315-6.

7 Bevan H, Fairman S. The New Era of Thinking and Practice in Change Transformation: A Call to Action for Leaders of Health and Care. NHS Improving Quality, 2014.

8 Wing JK, Beevor AS, Curtis RH, Park SB, Hadden S, Burns A. Health of the Nation Outcome Scales (HoNOS). Research and development. Br J Psychiatry 1998; 172: 11-8.

9 Wing J, Curtis RH, Beevor A. Health of the Nation Outcome Scales (HoNOS). Glossary for HoNOS score sheet. Br J Psychiatry 1999; 174: 432-4.

10 Burns A, Beevor A, Lelliott P, Wing J, Blakey A, Orrell M, et al. Health of the Nation Outcome Scales for elderly people (HoNOS 65+). Br J Psychiatry 1999; 174: 424-7.

11 Gowers SG, Harrington RC, Whitton A, Lelliott P, Beevor A, Wing J, et al. Brief scale for measuring the outcomes of emotional and behavioural disorders in children. Health of the Nation Outcome Scales for children and adolescents (HoNOSCA). Br J Psychiatry 1999; 174: 413-6.

12 Roy A, Matthews $H$, Clifford P, Fowler V, Martin DM. Health of the Nation Outcome Scales for People with Learning Disabilities (HoNOSLD). Br J Psychiatry 2002; 180: 61-6. 
13 Dickens G, Sugarman P, Walker L. HoNOS-secure: A reliable outcome measure for users of secure and forensic mental health services. J Forens Psychiatry Psychol 2007; 18: 507-14.

14 Fleminger S, Leigh E, Eames P, Langrell L, Nagraj R, Logsdail, S. HoNOS$\mathrm{ABI}$ : a reliable outcome measure of neuropsychiatric sequelae to brain injury? Psychiatrist 2005; 29: 53-5.

15 Macdonald AJ, Elphick M. Combining routine outcomes measurement and 'Payment by Results': will it work and is it worth it? Br J Psychiatry 2011; 199: 178-9.

16 Rathod S, Lloyd A, Asher C, Baird J, Mateus E, Cyhlarova E. Lessons from an evaluation of major change in adult mental health services: effects on quality. J Ment Health 2014; 23: 271-5.

17 National Collaborating Centre for Mental Health. Borderline Personality Disorder: the NICE guideline on Treatment and Management. National Clinical Practice Guideline No. 78. British Psychological Society \& Royal College of Psychiatrists, 2009.

18 Chaplin R, Perkins R. HoNOS: a cautionary tale of their use in a rehabilitation service. Psychiatr Bull 1999; 23: 20-1.

19 Pirkis JE, Burgess PM, Kirk PK, Dodson S, Coombs TJ, Williamson MK. A review of the psychometric properties of the Health of the Nation Outcome Scales (HoNOS) family of measures. Health Qual Life Outcomes 2005; 3: 76.
20 Powell AE, Davies HT, Thomson RG. Using routine comparative data to assess the quality of health care: understanding and avoiding common pitfalls. Qual Saf Health Care 2003; 12: 122-8.

21 Speroff T, O'Connor GT. Study designs for PDSA quality improvement research. Qual Manag Health Care 2004; 13: 17-32.

22 Walley P, Gowland B. Completing the circle: from PD to PDSA. Int J Health Care 2004; 17: 349-58.

23 Langley GJ, Nolan KM, Nolan TW, Norman CL, Provost LP. The Improvement Guide: A Practical Approach to Enhancing Organizational Performance. Jossey-Bass Publishers, 1996.

24 Marks I. Overcoming obstacles to routine outcome measurement. The nuts and bolts of implementing clinical audit. Br J Psychiatry 1998; 173: 281-6.

25 NHS England. The Friends and Family Test: Guidance. NHS England, 2014.

26 Coulter A. Collecting data on patient experience is not enough: they must be used to improve care. BMJ 2014; 348: 2225.

27 Bevan G, Hood C. What's measured is what matters: targets and gaming in the English public health care system. Publ Admin 2006; 84: 517-38.

28 Chrystal KA, Mizen PD. Goodhart's Law: its origins, meaning and implications for monetary policy. Available at http://www.cyberlibris. typepad.com/blog/files/Goodharts_Law.pdf (accessed September 2016)

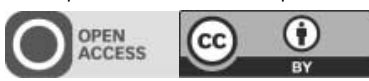

\title{
Personalisation and social care assessment - the Care Act 2014
}

\author{
Deb Barnes, ${ }^{1}$ Billy Boland, ${ }^{1}$ Kathryn Linhart, ${ }^{1}$ Katherine Wilson ${ }^{1}$
}

BJPsych Bulletin (2017) 41, 176-180, doi: 10.1192/pb.bp.116.053660

\begin{abstract}
${ }^{1}$ Hertfordshire Partnership NHS Foundation Trust

Correspondence to Billy Boland (billy.boland@hpft.nhs.uk)

First received 13 Jan 2016, final revision 9 Aug 2016, accepted 14 Sep 2016

(C) 2017 The Authors. This is an openaccess article published by the Royal College of Psychiatrists and distributed under the terms of the Creative Commons Attribution License (http:// creativecommons.org/licenses/by/ 4.0), which permits unrestricted use distribution, and reproduction in any medium, provided the original work
\end{abstract} is properly cited.
Summary The Care Act 2014 represents a significant change in legislation in England. For the first time it brings together various aspects of adult social care into a single statute succeeding earlier acts and policy. Given its importance to the lives of service users and carers, clinicians need to have a clear understanding of its implications. We provide an overview of why it was developed, its underlying principles and international comparisons, as well as implications for assessments, interventions and outcomes. The impact on the lives of patients and carers is discussed, as well as dilemmas and challenges the Act presents. While it addresses other important aspects of social care, including safeguarding, Mental Health Act section 117 aftercare and duty of candour, we focus on personalisation because of the opportunities it provides to enhance management plans for people experiencing mental health problems.

\section{Declaration of interest None.}

\section{Why was the Care Act 2014 developed?}

The Care Act 2014 represents the latest evolution in current attitudes to care. It was asserted by Norman Lamb MP, Care and Support Minister in the UK coalition government, as 'the most significant reform of care and support in more

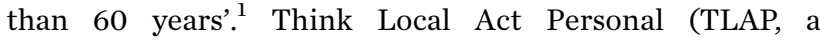
partnership of more than 50 organisations, including the National Health Service (NHS), 'committed to transforming health and care through personalisation and communitybased support' (www.thinklocalactpersonal.org.uk/About-us/)) sees it as representing a significant change in legislation, of importance to service users and carers in England and Wales because 'for the first time it puts them in control of their care and support. It also makes clear what kind of care they should expect' (www.thinklocalactpersonal.org.uk/ Browse/careact2014/). 